\title{
THE SCIENTIFIC AND TECHNICAL EVALUATION OF THE EFFECTIVENESS OF THE RESULTS OF RESEARCH AND DEVELOPMENT WORKS
}

\author{
Iryna Metoshop* \\ Department of Applied Economies \\ Ivano-Frankivsk National Technical \\ University of Oil and Gas \\ Ivano-Frankivsk, Ukraine \\ metoshop07@ukr.net
}

\author{
Alexandra-Anna Metoshop \\ Faculty of Economics \\ Taras Shevchenko National University \\ of Kyiv \\ Kyiv, Ukraine \\ metoshop25@gmail.com \\ Natalia Yashcheritsyna \\ Department of Applied Economies \\ Ivano-Frankivsk National Technical \\ University of Oil and Gas \\ Ivano-Frankivsk, Ukraine \\ yashcheritsyna@gmail.com
}

\author{
Ludmila Voitkiv \\ Department of Applied Economies \\ Ivano-Frankivsk National Technical \\ University of Oil and Gas \\ Ivano-Frankivsk, Ukraine \\ voitkivls@gmail.com
}

\begin{abstract}
The article deals with the basic approaches to the evaluation of research works, which make it possible to determine the level of expediency of their implementation, rationally distribute the amounts of funding, scientific potential that contributes to the development of scientific and technological progress.

Estimating the economic efficiency of $R \& D$ projects in the early stages of project implementation is predictive. The qualitative aspect of scientific research is characterized by the result, the content of which is checked by novelty. Therefore, the evaluation of the scientific and technical performance of the research and development work at the initial stage can be carried out only on the basis of the experience and knowledge of scientists acting as experts. In this case, the weighted point estimation and pairwise comparisons method is used.
\end{abstract}

The paper proposes the basic provisions for evaluating the scientific and technical efficiency of the results of research and development work at the initial stage, namely, the basic parameters for the evaluation of scientific efficiency; scientific and applied efficiency and technical efficiency.

The paper also formulates parameters for individual R\&D, which may have their own characteristics, namely, due to the nature of the study, experts can identify other performance indicators, such as environmental, social, financial, management, etc.

According to the results of the proposed method, the evaluation of the development of the use of de-cement solutions for the isolation of inflow of reservoir water to the downhole of gas and gas-condensate wells of the PreCarpathian region was made and the corresponding conclusions were drawn.
The proposed $R \& D$ methodology will enable the implementation of efficient, high-efficiency developments that will bring profit to the enterprise in the future and ensure its competitiveness..

Keywords- scientific research, $R \& D$ works, evaluation method, efficiency, integral indicator, options.

\section{FORMULATION OF THE PROBLEM}

In conditions of innovative development of the economy, questions of assessing the feasibility of the introduction and financing of research and development work are becoming more and more often posed. This is a creative activity, in particular, inventions, useful models, industrial designs, know-how, selection achievements, scientific and technical information and other objective results of human intellectual work, aimed at knowledge of the environment and the use of accumulated knowledge for its needs. To ensure its own competitiveness, each company is interested in conducting and implementing effective $\mathrm{R}$ \& $\mathrm{D}$. The state is also interested in this, as the development of modern technologies and advanced developments also ensures the development of the national economy. Assessment of R \& D provides an opportunity to determine the level of feasibility of their implementation, rational allocation of funding, scientific potential and contributes to the development of scientific and technological progress.

The purpose of the article. Propose a methodological approach to assess the scientific and technical efficiency of research and development works.

\section{ANALYSIS OF RECENT RESEARCHES AND PUBLICATIONS}

Methodological approaches to the evaluation of these types of work were formed in the early 90's. A number of 
legislative acts were approved at the state level, as well as a number of normative documents on the planning, accounting and calculation of the cost of research and development works, calculating of economic efficiency of expenses for scientific researches and development and their introduction into production, standards of organization and conducting research work, etc.

The issue of $\mathrm{R} \& \mathrm{D}$ is given attention in the writings of Hariv P. S., Yatsenko N. M., Boychik I. M. [1], where they are substantiating the necessity of standardization of research and experimental design and experimental works.

Kharchuk V.Yu., Dubik M.Ya. [2] examine the causes of $\mathrm{R} \& \mathrm{~S}$ risks, in particular, factors that influence the formation of risks at all stages of $\mathrm{R} \& \mathrm{D}$, from fundamental research to $\mathrm{R} \& \mathrm{D}$.

Neroda-Berezka K.I. [3] analyzes the main factors determining the process of internationalization of the research activities of transnational firms, to distinguish the main groups of motives that determine this process, depending on their power of influence and significance.

Karpov V.A, Koroleva T.S, Podgorny A.Z. [4] investigate the main provisions of the methodology for determining the effectiveness of research work to assess the cost of scientific research in higher education.

Most works assess scientific developments from the positions of future cash flows that will be obtained as a result of their implementation. However, as correctly stated by V.A. Karpov, T.S. Koroleva, A.Z. Pidgornyi the underlying [4] scientific and technical performance of $\mathrm{R} \&$ $\mathrm{D}$ cannot be estimated using the method of discounting cash flows, since there is no market product as a result of research, except those situations when the research has the value characteristics of the $R \& D$ result as a scientific and technical product, which receives the customer.

In the writings of foreign publications, as noted [5], much of the research focused on the development of conceptual models for measuring R\&D productivity. Some studies propose to use a balanced scorecard to measure R\&D productivity through the assessment of financial, customer, internal business processes and their prospects based on an integrated evaluation system.

The studies [6] distinguish the following methods of measuring efficiency:

classical - indicator methods, parametric methods, nonparametric methods.

However, as noted in [6], the indicator, which is used in classical models, does not make it possible to assess whether $\mathrm{R} \& \mathrm{D}$ will be effective in the future, or allows comparison with only existing counterparts.

Disadvantages of analysis by classic methods, most often highlighted by the authors: one-dimensional nature and fuzzy interpretation of atypical observations.

The main parametric methods include: stochastic frontier analysis (SFA), distribution-free approach (DFA) and others.

As noted in [7], the parametric approach makes it possible to test hypotheses, take into account their statistical errors, and provides an estimation of parameters of production factors, elasticity, etc. But these methods have some disadvantages, in particular, of imposing on some basis the functional form of the boundary to be evaluated (although it may be variable) [7].

Non-parametric methods: Data Envelopment Analysis (DEA) and Free Disposal Hull (FDH).

A lot of scientists are inclined to use nonparametric methods, namely the data analysis method (DEA), when evaluating technical effectiveness, these methods are described in [5], [6], [8], [9], [10].

Nonparametric methods were first used in the works of Farrell (1957) and Debre (1951) [5], [9]. Establishing efficiency is to calculate how much the cost required to produce these results can be minimized.

As noted in [5], the nonparametric approach is not bounded by any conditions and can easily measure the decision-making units (DMU). The DEA has several advantages: it allows multiple outputs and multiple inputs to be analyzed at the same time and does not require production volumes.

[8] noted that all models are divided into input-oriented and output-oriented models, depending on the destination.

Input-oriented models minimize input while maintaining a constant output signal, and output-oriented models maximize output while maintaining an input constant.

In [9], the author proposes to use a technical scale and economic model based on DEA in the study.

However, as the authors note in their works, these techniques have several disadvantages, which are generally related to the limited data available to conduct comprehensive assessment, including external factors.

In the DEA, it is impossible to identify the technology that can be limiting in most cases, and to evaluate the parameters and test the hypotheses [9].

Based on the analysis of scientific works, we have come to the conclusion that most of the studies, which were considered, are aimed at evaluating the work of scientific units or the activity of the enterprise, which does not allow to distinguish the impact of specific R\&D.

Therefore, in order to develop a common approach to assessing research and development in different sectors of the economy, this issue needs further development.

\section{MAIN RESULTS OF THE STUDY}

The probable nature of the results of research and development work complicates the assessment of their economic efficiency, which can lead to the stages and duration of development. The application of these difficulties uses the method of assessing the certainty of economic efficiency with an appropriate degree of accuracy. In the early stages of project work, these calculations are predictable.

The qualitative aspect of scientific research characterizes the result, the content of which is checked by novelty. Therefore, we think that evaluation of the scientific and technical effectiveness of research and development work at 
an initial stage can only be carried out on the basis of the experience and knowledge of the scientists who act as experts. In this case, we use the method of weighted ball scores and pairwise comparisons.

All parameters can be divided into three groups: scientific efficiency; scientific and applied efficiency; technical efficiency.

Individual $\mathrm{R}$ \& $\mathrm{D}$ can have its own peculiarities, therefore, due to the nature of the research, experts may also highlight other performance indicators such as environmental, social, financial, managerial, etc.

To evaluate the performance for each parameter group we suggest to use the formula (1):

$$
I_{g r j}=\sum_{i=1}^{n} a_{i} q_{i},
$$

where $I_{g r j}$ - integral index $j$-th group parameter;

$\mathrm{a}_{\mathrm{i}}$ - score of the $\mathrm{i}$-th parameter;

$\mathrm{q}_{\mathrm{i}}$ - weight of the $\mathrm{i}$-th parameter in the group;

$\mathrm{i}$ - parameter in the group;

$\mathrm{n}$ - number of parameters in the group;

$\mathrm{j}$ - the group parameter number.

On the basis of the evaluation, it is necessary to determine the generalizing integral parameter by the formula (2):

$$
I_{\text {genk }}=\sum_{j=1}^{m} I_{g r j} W_{j},
$$

where $\mathrm{W}_{\mathrm{j}}$ is the weight of the $\mathrm{j}$-group;

$\mathrm{m}$ - the number of group parameters.

$\mathrm{k}$ - an expert participating in the assessment.

The factors proposed in the paper [4] can be taken as the basis for the formation of scientific and applied research, namely the scientific level, novelty and depth and the degree of dissemination of ideas and developments - for the evaluation of scientific efficiency and the prospect of using the results of $R \& D$, the scale of implementation of results, quality results - to evaluate scientific and applied performance. To evaluate the technical effectiveness we propose to use such parameters as: probability of technical success, patent purity, uniqueness of products (lack of analogues), availability of scientific and technical resources necessary for the implementation of the project, availability of scientific and technical resources necessary for implementation, compliance with the draft scientific strategy-experience at the enterprise, cost of development, possible future development and application of new technology, effect on other projects, patentability (or possible patent protection of the project).

Quantitative indicators, such as the level of technical equipment of labor, the share of new technologies by volume and complexity of production, productivity of machinery, its reliability and durability, the level of automation and mechanization of production and labor, can be used to evaluate the technical effectiveness and comparison of R\&D with analogues.

Some research developments may have an impact on financial, environmental, managerial, sociological or other activities of the enterprise.

In general, these features, to our mind, can be estimated using such the parameters as: compliance with the objectives, fulfillment of obligations (requirements), business reputation, level of management benefits, value of energy saving, environmental aspect, hygiene and safety of work, industrial safety, management system, probability of risk of execution.

For a more in-depth assessment of the $R \& D$, at the discretion of experts, we suggest to supplement this method by other parameters, in particular:

1) environmental performance;

For this group, we suggest to use the following parameters: the degree of reduction of the load on the environment; consequences of environmental changes for public health, consequences for nature and biodiversity; conformity of scientific research works to environmental legislative acts, norms and standards; the level of achievement of target and planned indicators of ecologization of activity; the degree of implementation of specialized environmental standards in practice; the degree of functional impact on the subject of the business.

2) managerial performance, namely: degree of consistency of research work with processes that occur in the external environment; the level of internal balance of policy; possibility of realization of the policy taking into account the available resource potential of the enterprise; the level of business reputation of the enterprise; increase of controllability of its structural subdivisions; financial expenses for management; level of coverage by management functions; the level of rationality of the structure;

3) financial performance, in particular: the efficiency of development, the level of increase financial sustainability of the entity, the degree of increase business activity of the business entity, the level of profitability, acceptability of the level of risks associated with the implementation of R\&D, etc.

4) sociological performance and working conditions.

To the fourth group of parameters we suggest to attribute: improving working and living conditions of employees, raising the level of material incentives and social satisfaction of staff; level of safety (mechanical damage, fire safety); the level of accidents; the level of working conditions (noise, vibration, heat factor, harmful working conditions); sanitary norms.

In particular, indicators of the level of relevance to environmental factors (political, economic, social, demographic, etc.) and the balance of interests of stakeholders (suppliers, stakeholder interests, suppliers) can be used to assess management performance by the degree of coherence of research with processes occurring in the external environment. , partners, etc.. An assessment of the internal balance of a policy parameter can be made using 
such indicators as the level of R\&D balance with strategic goals, the $\mathrm{R} \& \mathrm{D}$ compliance with the anticipated level of management risks and others. We suggest to evaluate the increase of controllability of structural divisions by the level of controllability, the coefficient of rationality of the structure, the coefficient of centralization of administrative functions. The level of coverage of management functions is the coefficient of completeness of coverage of management functions, the coefficient of duplication of functions, the coefficient of depth of specialization of management work, etc.

According to the definition of all experts, the average integral summary indicator of scientific and technical efficiency is recognized by the formula (3):

$$
I_{\text {en.aver. }}=\frac{\sum_{k=1}^{t} I_{\text {genk }}}{t},
$$

where, $\mathrm{t}$ - number of experts participating in the assessment.

Experts' assessments can with greater degree of reliability reflect performance, but the subjectivity of assessments is always controversial. Therefore, for more precision of the results, in our opinion, several experts are required. If, in the assessment, there is a problem of consensus of experts, a comprehensive assessment of the consistency of expert opinions we suggest to obtain with the help of the coefficient of concordance (the total coefficient of concordance) according to the formula offered by Kendel (4):

$$
\omega=\frac{12 \sum_{j=1}^{m}\left[\sum_{k=1}^{t} x_{i k}-\frac{\sum_{k=1}^{t} \sum_{i=1}^{n} x_{i k}}{m}\right]^{2}}{t^{2}\left(m^{3}-m\right)},
$$

where $\omega$ - coefficient of Kendel concordat;

$x_{i \kappa}$ - ranks determined on the basis of group integral indicators of experts;

$\mathrm{t}$ - the number of experts participating in the assessment;

$\mathrm{m}-$ the number of group parameters.

At low coefficient of concordance, it is worth to improve the composition of experts by excluding experts with the maximum deviations from the average opinion and conduct the second round of examination.

According to the results of experts, determine the level of scientific and technical efficiency using the scale shown in Table 1.

TABLE I. THE INTEGRAL LEVEL ACHIEVED

\begin{tabular}{|l|c|}
\hline \multicolumn{1}{|c|}{ Level } & Scores \\
\hline High & $100-71$ \\
\hline Sufficient & $70-31$ \\
\hline Low & $\leq 30$ \\
\hline
\end{tabular}

In cases where scientific and technical products are the product of sale, which the customer buys, the results of the research have the cost characteristics of $R \& D$ results. That is, in this case, the actual effectiveness of the R\&D arises, which can be estimated by the cost of conducting the R\&D (B) and the profit that the developer wants to get (C).

Costs are determined in accordance with "Typical regulations for the planning, accounting and calculation of the cost of research and development" [11].

Consider the use of the proposed method in the example.

The use of decomposition solutions for the isolation of the reservoir water flow to the gas and gas condensate wells of the Precarpathian deposits, a detailed description of which is given in the paper [12].

Experts from IFNTU of Oil and Gas and State Enterprise "Lvivgazvydobuvannya" were involved in the evaluation of research results. The results of experts' evaluations for the determination of scientific research results of R\&Ds by the proposed method are summarized in Table 2 .

\begin{tabular}{|c|c|c|c|c|c|}
\hline \multirow{2}{*}{$\begin{array}{c}\text { Integr. } \\
\text { package }\end{array}$} & \multicolumn{3}{|c|}{ Experts } & \multirow{2}{*}{$\begin{array}{c}\text { Group of } \\
\text { parameters }\end{array}$} & \multirow{2}{*}{$\begin{array}{c}\text { Sum of } \\
\text { ranks }\end{array}$} \\
\hline & 1 & 2 & 3 & & \\
\hline $\mathrm{I}_{\mathrm{gr} 1}$ & 59 & 58,5 & 46,5 & $\begin{array}{l}\text { scientific } \\
\text { efficiency }\end{array}$ & 3 \\
\hline $\mathrm{I}_{\mathrm{gr} 2}$ & 65,5 & 74 & 80 & $\begin{array}{l}\text { technical } \\
\text { efficiency }\end{array}$ & 7 \\
\hline $\begin{array}{c}\text { Average } \\
\text { integral } \\
\text { summary } \\
\text { indicator }\end{array}$ & $\begin{array}{l}74,25 \\
67,7\end{array}$ & $\begin{array}{l}71,25 \\
68,53\end{array}$ & $\begin{array}{l}72,25 \\
67,24\end{array}$ & $\begin{array}{c}\text { scientific and } \\
\text { applied } \\
\text { efficiency }\end{array}$ & 8 \\
\hline
\end{tabular}

TABLE II. MATRIX OF EXPERT ASSESSMENTS

The experts gave scores of the achieved level from 0 to 100 for each proposed parameter and their characteristics, and set their weighting coefficients, as well as set the weight of each group of parameters for this study. Using formulas (1), (2) and (3) we calculated the magnitude of the group integral indices and the generalized integral index.

Experts' estimates on the parameters of scientific efficiency ranged from 46.5 to 59 points, from scientific and applied from 65.5 to 80 points and from technical ones from 71.25 to 74.25 .

Consequently, the most significant result is achieved by the group of scientific and applied efficiency and technical efficiency.

According to the definition of all experts, the average integral summary indicator of scientific and technical efficiency:

$$
I_{\text {en.aver. }}=\frac{67,7+68,53+67,24}{3}=67,82
$$

According to the achieved value, we state a sufficient level of scientific and technical efficiency of the proposed R\&D.

The Kendel coefficient we extend $(0,778)$ trusts the height level of agreement between expert opinions. 
The proposed methodology for $\mathrm{R} \& \mathrm{D}$ evaluation will enable the implementation of effective development with a high degree of performance, which in the future will bring profit to the company and ensure its competitiveness.

\section{CONCLUSIONS}

According to the results the following conclusions are made:

1. Most papers evaluate scientific developments from the perspective of future cash flows that will result from their implementation. However, the scientific and technical performance of the GDR and the SCR cannot be estimated using the cash flow discount method because there is no market product as a result of research.

2. The probabilistic nature of the results of research and development activities complicates the evaluation of their economic efficiency, so to avoid difficulties, it is necessary to use the method of gradual determination of economic efficiency with increasing degree of accuracy.

The qualitative aspect of scientific research is characterized by the result, the content of which is checked by novelty. Therefore, the evaluation of the scientific and technical performance of the research and development work at the initial stage can be carried out only on the basis of the experience and knowledge of scientists acting as experts.

3. Classical, parametric and non-parametric methods are proposed in the works of foreign editions. However, as the authors note in their works, these techniques have several disadvantages, which are generally related to the limited data available to conduct comprehensive assessment, including external factors.

4. We are proposed to use the method of weighted point estimates and pairwise comparisons. At the same time, we have divided all parameters into three groups: scientific efficiency; scientific and applied efficiency; technical performance, as well as additional options for evaluating individual research developments that may have an impact on the financial, environmental, management, sociological or other activities of the enterprise.

5. Approbation of the methodology on the example of the evaluation of scientific development on the use of degenerate solutions for isolation of inflow of reservoir water to the downhole of gas and gas-condensate wells of the Precarpathian region, showed that the most significant result was achieved by the group of scientifically applied efficiency and technical efficiency. In general, according to the achieved value of the integral generic indicator of scientific and technical efficiency, it is concluded that there is a sufficient level of scientific and technical efficiency of the proposed GDR.

The Kendel coefficient calculated by us $\omega=0.778$ indicates a high degree of agreement between experts' opinions.
6. The proposed $R \& D$ methodology will enable the implementation of effective, high-efficiency developments that will bring profit to the enterprise in the future and ensure its competitiveness.

\section{REFERENCES}

[1] P. S. Khariv, N. M. Yatsenko, I. M. Boychik, O. P. Vashkiy and O. M Sobko "Rationing of scientific research, experimental design and experimental works", Ternopil, 32 p. 1996, ( in Ukraine).

2] V. Yu. Kharchuk and M. I. Dubik "Risk of research and development: the essence and features of occurrence", Management and entrepreneurship in Ukraine: stages of development and development problems, vol. 727, Lviv Polytechnic, pp. 387-392, 2012, ( in Ukraine).

[3] K. I. Neroda-Berezka "Research activity of transnational firms: modern determinants of internationalization", Current problems of international relations, vol. 122 (Part II), pp. 165-170, 2014, ( in Ukraine).

[4] V. A Karpov, T.S.Korolova and A.Z.Pidgorny "Methodology for evaluating the effectiveness of research work", Odesa: ODEU, rotatrint, 19 p, 2005, ( in Ukraine).

[5] Yung-Hsiang Lu., Chung-Chi Shen, Chung-Te Ting, and ChunHsien Wang "Research and development in productivity measurement: An empirical investigation of the high technology industry", African Journal of Business Management, vol. 4(13). pp. 2871-2884, 2010

[6] J. Wolshchak-Derlach " The scientific, didactic and implementation efficiency of state universities in Poland - analysis nonparametric", Gdansk, 189 p, 2013, (in Poland). [Online]. Available: http://pbc.gda.pl/Content/44669/Wolszczak-Derlacz.pdf. Accessed on: May, 2019.

[7] Subal C. Kumbhakar, R. Ortega-Argilés, L. Potters , M. Vivarelli and P. Voigt "Corporate R\&D and Firm Efficiency: Evidence from Europe's Top R\&D Investors", Sevilla Discussion, IZA DP, vol. 4657, 29 p., 2009, [Online]. Available: http://citeseerx.ist.psu.edu/viewdoc/download?doi=10.1.1.649.333\&re $\mathrm{p}=$ rep1\&type $=$ pdf. Accessed on: May, 2019.

[8] Jung Ho Park and Kwangsoo Shin "Efficiency of GovernmentSponsored R\&D Projects", Sustainability, 10(7), 2018. Available: http://www.mdpi.com/journal/sustainability. Accessed on: May, 2019.

[9] M. Umanath and D. David Rajasekar "Estimation of Technical, Scale and Economic Efficiency of Paddy Farms: A Data Envelopment Analysis Approach", Journal of Agricultural Science, vol. 5. Madras Institute of Development Studies, pp.243-251, 2013. Available: https://www.researchgate.net/publication/270645013_Estimation_of_ Technical_Scale_and_Economic_Efficiency_of_Paddy_Farms_A_Da ta_Envelopment_Analysis_Approach. Accessed on: May, 2019

[10] J. Jakushewich "Analysis and assessment of the productivity of scientific units", Poznan University of Technology, 336 p., 2015, (in Poland). [Online]. Available: http://repozytorium.put.poznan.pl/Content/346794/Joanna_Jakuszewi cz_Analiza_i_ocena_produktywnosci_jednostek_naukowych.pdf. Accessed on: May, 2019.

[11] Verkhovna Rada of Ukraine. "Typical position on the planning, accounting and calculation of the cost of research and development work", Document 830-96-ח, the action is restored, the current edition - Revision of 03.03.2011, the basis - 126-2011, ( in Ukraine). [Online]. Available: http://zakon.rada.gov.ua/laws/show/830-96$\%$ D0\%BF. Accessed on: May, 2019.

[12] O.M. Chornyi "Geological factors of influence on the disclosure and development of gas-bearing layers of the pre-Carpathian deflection outer zone", Thesis for a candidate degree in geological sciences. Ivano-Frankivsk, pp.149-166, 2011. 